\title{
Polyorchidism Presenting with Testicular Pain and Scrotal Mass
}

\author{
Serdar Aykan ${ }^{1}$, Mustafa Zafer Temiz ${ }^{2 *}$, Murat Tuken ${ }^{1}$ and Emrah Yuruk ${ }^{1}$ \\ ${ }^{1}$ Department of Urology, Bagcilar Training and Research Hospital, Bagcilar, Istanbul \\ ${ }^{2}$ Department of Urology, Bitlis State Hospital, Besminare, Bitlis, Istanbul
}

"Corresponding Author: Mustafa Zafer Temiz, Department of Urology, Bitlis State Hospital, Besminare Mh. 13000, Besminare, Bitlis, Istanbul, Tel: +90 434 246 84 20; Fax: +90 43424684 24; E-mail: dr_mustafazafertemiz@hotmail.com

Rec date: Jan 21, 2015, Acc date: Feb 23, 2015, Pub date: Feb 28, 2015

Copyright: (C) 2015 Aykan S, et al. This is an open-access article distributed under the terms of the Creative Commons Attribution License, which permits unrestricted use, distribution, and reproduction in any medium, provided the original author and source are credited.

\begin{abstract}
Background: Polyorchidism is an extremely rare congenital anomaly of the urogenital system and is defined as the presence of more than two testes. The majority of patients are asymptomatic or present with painless inguinal or scrotal masses. We, hereby, report a 25 -year-old triorchidism case who presented with testicular pain and a scrotal mass. Case report: A 25-year-old male patient was admitted to the outpatient clinic with the complaint of testicular pain and a scrotal mass. His medical history was unremarkable and there was no history of trauma. On physical examination, there were two palpable, ovoid, mobile, non-tender masses in the left hemiscrotum. Scrotal Color Doppler Ultrasonography revealed a $1.5 \times 2.0 \times 1.2 \mathrm{~cm}$, well-circumscribed accessory tissue in the left hemiscrotum which had same echogenicity as the normal testes. Magnetic Resonance Imaging (MRI) also confirmed the tissue as the third testis. The patient was managed conservatively and put into a follow-up program.
\end{abstract}

Conclusion: Polyorchidism is a rare congenital anomaly. Patients with polyorchidism can be managed conservatively unless there is no accompanying problems such as inguinal hernia, cryptorchidism or torsion. However, supernumerary testes should be removed if there is a suspicion for malignancy.

Keywords: Scrotal mass; Testicular pain; Polyorchidism

\section{Introduction}

Polyorchidism is an extremely rare congenital anomaly of the urogenital system and is defined as the presence of more than two testes [1]. Its most common presentation is triorchidism [2]. The left side is predominantly affected. Approximately $50 \%$ of the cases are detected between 15 and 25 years of age [3]. The majority of patients are asymptomatic or present with painless inguinal or scrotal masses, undescended testis, and rarely, torsion of the supernumerary testis [4].

We, hereby, report a 25-year-old triorchidism case who presented with testicular pain and a scrotal mass.

\section{Case Presentation}

A 25-year-old male patient was admitted to the outpatient clinic of Bagcilar Training and Research Hospital, Istanbul with the complaint of testicular pain and a scrotal mass. His medical history was unremarkable and there was no history of trauma. On physical examination, his right testis was in normal shape and location; however, there were two palpable, ovoid, mobile, non-tender masses in the left hemiscrotum. There were no signs of inguinal hernia or hydrocele.

Scrotal colour Doppler ultrasonography revealed a $1.5 \times 2.0 \times 1.2$ $\mathrm{cm}$, well-circumscribed accessory tissue in the left hemiscrotum which had same echogenicity as the normal testes. The accessory tissue had its own vascular system and epididymis draining to a common vas, suggestive of an accessory testis (Figure 1). Magnetic Resonance Imaging (MRI) also confirmed the tissue as the third testis (Figure 2).

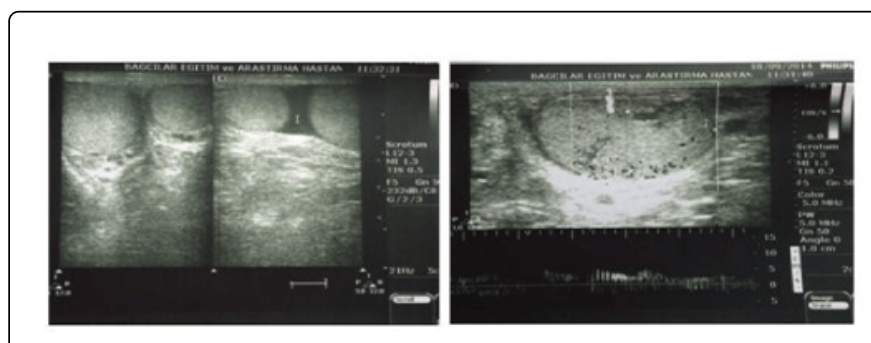

Figure 1: Color Doppler ultrasonography images of the left hemyscrotum: An extra smaller testicle with similar echo texture and vascular flow as the normal testes.


Figure 2: Coronal magnetic resonance images of scrotum: T1/T2weighted magnetic resonance images show three testes very clearly. The supernumerary testicle is smaller and it has similar intensity with normal right and left testes. 
The patient was managed conservatively and put into a follow-up program.

\section{Discussion}

Blasius was first described the case of a polyorchidism at routine autopsy in 1670 [5].

Although polyorchidism can be suspected on clinical or macroscopic examination, the supernumerary testes should be confirmed by histological assessment. The first description of supernumerary testes with histological confirmation was reported by Lane in 1895 [6].

Triorchidism is the most common form of polyorchidism, in which an extra testicle is usually found on the left side [2]. Several locations have been described at any point along the way of embryological testicular descent to its final scrotal location [7].

The etiology of polyorchidism is still unknown. However, it could be related to an embryological developmental abnormality during the formation of the testicles [2].

The possible etiologic mechanism is a defect of genital ridge before 8 weeks of fetal development, such as a longitudinal or transverse division or duplication of genital ridge with or without the Wolffian duct division [8].

In their meta-analysis, Bergholz et al. identified only 178 reports (191 cases) of polyorchidism [9]. Of the cases, 140 (73\%) were histologically confirmed and 51 (27\%) were diagnosed solely by ultrasound or MRI. The authors introduced a guideline for its management based on a functional classification of polyorchidism.

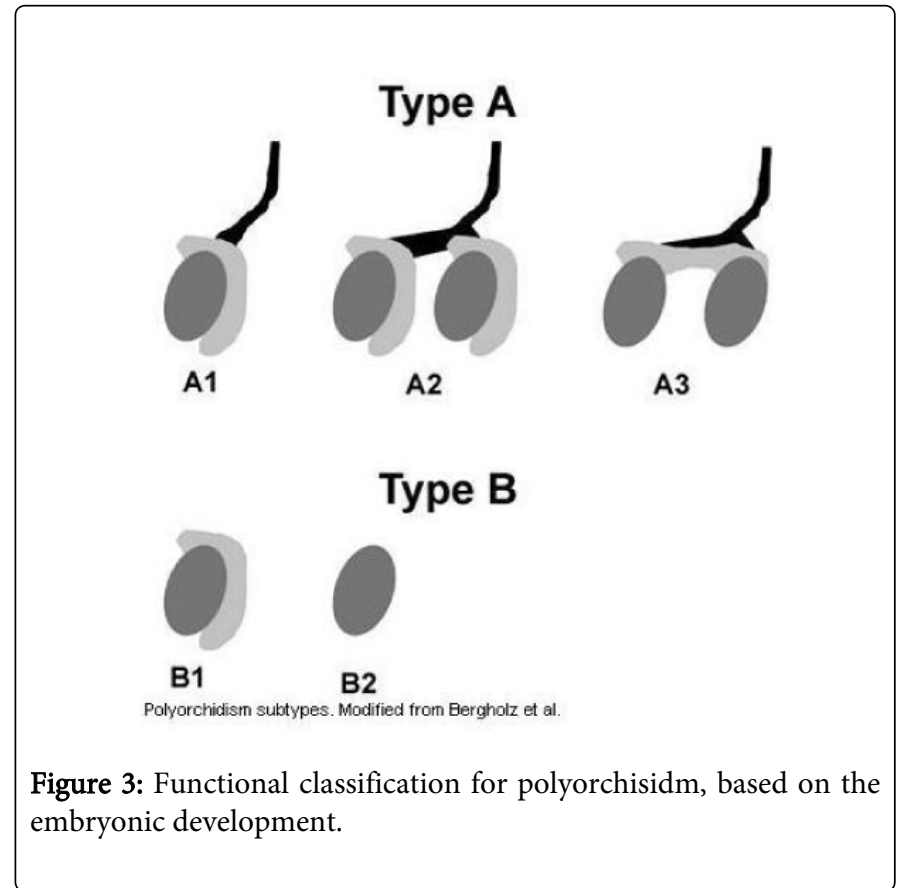

Thum reported a functional classification for polyorchisidm, based on the embryonic development as follows: type 1, the supernumerary testis does not have epididymis and vas deferens; type 2, the supernumerary and the regular testes are linked to each other with a common epididymis and they both have a common vas deferens (incomplete division); and type 3 (complete division), the supernumerary testis has its own epididymis but its vas deferens is shared with the regular testis [10] (Figure 3). Therefore, our case fits in type 3.

There are some associated pathologies with polyorchidism such as inguinal hernia (24\%-30\%), cryptorchidism (15\%-40\%), testicular torsion (13\%-15\%), hydrocele (9\%), pain (7\%), hypospadias, persistence of Móller ducts (7\%-9\%), chromosome alterations (3\%), testicular cancer (6\%) and varicocele (1\%-1.4\%).

Most cases in the literature were diagnosed during exploration for other pathologies such as inguinal hernia (24\%), undescended testis (22\%), and testicular torsion (15\%) [7]. Left triorchidism was the most frequent presentation (65\%), and the majority of supernumerary testes were found in the scrotal region (66\%), followed by inguinal (23\%) and abdominal (9\%) locations [8]. The third testis of the case presented in this report was located in scrotum.

Management of polyorchidism has been a subject of debate. Formerly, it was a common practice to remove the supernumerary testis, regardless of whether it was in scrotal, inguinal or abdominal position because of the risk of torsion and/or malignancy [4]. With recent improvements in imaging studies, an increasing number of cases are diagnosed via ultrasonography or MRI. Some of these cases have been left in situ and followed conservatively. Since testicular malignancy has been reported in as much as $6 \%$ of cases with polyorchidism and approximately $90 \%$ of these were detected in cryptorchid testes, all suspicious intrascrotal masses should be screened with serum markers and radiological techniques, regardless of physical examination findings. Although there are no clear guidelines to determine which cases can be followed conservatively, recent data support watchful waiting in the absence of concomitant abnormalities and if testicular malignancy can be ruled out safely [8].

Polyorchidism is a rare congenital anomaly. Patients with polyorchidism can be managed conservatively unless there are no accompanying problems such as inguinal hernia, cryptorchidism or torsion. However, supernumerary testes should be removed if there is a suspicion for malignancy.

\section{References}

1. Sheah K, Teh HS, Peh OH (2004) Supernumerary testicle in a case of polyorchidism. Ann Acad Med Singapore 33: 368-370.

2. Artul S, Habib G (2014) Polyorchidism: two case reports and a review of the literature. J Med Case Rep 8: 464.

3. Gardiner RA, Samaratunga ML, Gwynne RA, Clague A, Seymour GJ, et al. (1996) Abnormal prostatic cells in ejaculates from men with prostatic cancer a preliminary report. Br J Urol 78: 414-418.

4. Leung AK (1988) Polyorchidism. Am Fam Physician 38: 153-156.

5. Ahlfeld F (1880) Die Missbildungen des Menschen. Leipzig, Germany.

6. Lane WA (1895) A case of supernumerary testis. Trans Clin Soc Lond 28: 59.

7. Avargues A, Rogel R, Broseta E, Luján S, Betancourt JA, et al. (2014) Polyorchidism: the case in a young male and review of the literature. Asian J Androl .

8. Jorion JL, Wese FX, Hennebert P, Vandervaeren D, Clapuyt P, et al. (1990) Polyorchidism: report of three cases and further embryological considerations. Eur Urol 17: 90-92.

9. Bergholz R, Wenke K (2009) Polyorchidism: a meta-analysis. J Urol 182: 2422-2427.

10. Thum G (1991) Polyorchidism: case report and review of literature. J Urol 45: 370-372. 